\title{
Looking in the Mirror: Expanding Female Leadership in Academic Medicine
}

\author{
Susan M. Flaherty ${ }^{1} \cdot$ Christopher J. Moran $^{3}$ - Shannon E. Scott-Vernaglia ${ }^{2}$ \\ Accepted: 14 June 2021 / Published online: 25 June 2021 \\ (C) The Author(s), under exclusive licence to Springer Science+Business Media, LLC, part of Springer Nature 2021
}

\begin{abstract}
"It's hard to be what you can't see." Marian Wright Edelman used those words in her appeal for a more diverse representation of children of color in literature and in classroom materials [1]. These words also resonate with female leaders in academic medicine calling for increased female representation, including their visual representation as portraits in the halls of power. Elizabeth Travis echoes Wright Edelman, "I'm a firm believer that 'if you can't see it, you can't be it." [2]. Travis belongs to a leadership group tasked with increasing the number of women in leadership positions at MD Anderson Cancer Center. Julie Silver, cancer rehabilitation specialist at Massachusetts General Hospital, led the 2017 Walls Do Talk Challenge for medical students to look around their environment and create alternative artwork that reflected education, wellness, healing, innovation, or diversity and inclusion [3]. Do the medical students who responded to that challenge work in an increasingly nurturing environment that promotes women and people of color to become division chiefs, professors, department chairs, and deans?

Investigating the issue of gender disparity in leadership circles in academic medicine creates a hydra-headed conundrum. As the authors examine one complex concern such as implicit bias, two more issues such as mentoring and networking or parental leave and family responsibilities arise. We begin anew with the measurement of the status quo, and the charge of how it can be fixed. Although we find some
\end{abstract}

Susan M. Flaherty

SMFLAHERTY@mgh.harvard.edu

1 Department of Pediatrics, Mucosal Immunology and Biology Research Center, Massachusetts General Hospital, Boston, USA

2 Department of Pediatrics, Massachusetts General Hospital Pediatric Residency Program, Massachusetts General Hospital, Boston, USA

3 Division of Pediatric Gastroenterology, Hepatology, and Nutrition, Massachusetts General Hospital, Boston, USA encouragement that progress is being made in the research study by Sethi et al., published in this issue of Digestive Diseases and Sciences, much work remains before a successful transformation to equitable leadership in terms of gender and race will occur. Equality in academic medical leadership will never be achieved until the complex issues of gender and racial inequity and bias are adequately addressed, and all members take ownership in addressing and measuring improvement in these areas. Promising trends are emerging, including more women than men entering medical school and rising numbers in specialties such as obstetrics and gynecology, though gastroenterology lags behind in terms of female representation and promoting women and people of color to leadership positions.

Given the unbalanced gender ratio in gastroenterology in general, with $81 \%$ male physicians and $18.9 \%$ female physicians in practice in 2019 [4], closing the male/female divide may resemble Sisyphus pushing his boulder up the hill. Sethi et al. share equally dismal gender leadership statistics: males represent $86 \%$ of chairs; $82 \%$ of division chiefs; $76 \%$ of program directors; and $63 \%$ of associate program directors. Perhaps most distressing, $43 \%$ of GI training programs have no female leaders. Not surprisingly, the researchers reported that a higher percentage of women trainees in gastroenterology fellowship programs were present when leadership positions such as chair, division chief, and fellowship director were occupied by women [5]. In organizations where women are leaders, more women follow in their footsteps. Nevertheless, female leadership alone did not entirely close the gap for individual programs.

If, as Sethi et al. state, a goal of the four major gastroenterology societies is to attract female physicians in more proportionate numbers, we must work collectively to improve gender ratios and leadership roles. In its statement on gender equity, the Association of American Medical Colleges (AAMC) calls for action in the areas of workforce, leadership, compensation, research, and recognition. According to the AAMC, the "power differentials" caused by an exclusion 
of women and a concentration of men in academic medicine put men in positions of power that "(1) control the careers of others and (2) choose whether to address equity issues." [6]. The AAMC's Group on Women in Medicine and Science provides resources and tools on gender equity, recruitment, retention, awards, and career advancement. In this editorial, we examine the key areas of mentorship, role models, family planning, and parental leave.

Building up female leadership in gastroenterology requires both supportive mentors and role models to augment the field of gastroenterology by developing a group of young scholars. Travis et al. demonstrated that $41 \%$ of practicing gastroenterologists lacked a highly effective mentor [7]. Beyond local efforts to improve mentor support, national leadership conferences such as the American Gastroenterological Association (AGA)'s Women's Leadership Conference enable gastroenterologists to expand their access to strong mentorship. These conferences also serve to augment the national portfolio of successful women in gastroenterology by focusing on existing and emerging female leaders. It is crucial for local leadership to not only support but also to actively advocate for their female faculty members to participate in these opportunities and include protected time off to attend as part of that support.

But before growing much-needed mentoring support for our future female academic leaders, we must first attract strong female candidates. National endeavors for aspiring gastroenterologists would also facilitate the development of mentoring relationships at a distance. Existing programs such as the American Association for the Study of Liver Diseases (AASLD) Foundation's Emerging Liver Scholars Program target aspiring residents who are considering the field of gastroenterology or hepatology. This particular program recruits highly competitive trainees, many of whom have already published a first-authored manuscript, and pairs them with an AASLD member at their own institution [8].

A parallel initiative to a highly competitive program would target a broader audience of applicants from smaller institutions, some of whom might have less access to established mentors. The Teaching and Tomorrow Program, facilitated by the North American Society of Pediatric Gastroenterology, Hepatology, and Nutrition, brings together interested pediatric trainees and leaders in pediatric gastroenterology, giving them access to needed mentors and sponsors. Programming can also provide the platform to showcase highly successful female gastroenterologists and hepatologists as role models and would send an important message to trainees. Travis puts it well, "The institutions that are performing the best in terms of gender equity are intentional about inviting more women to the table and shining a light on their successes." [9].

To attract and retain talented female scholars, we must also examine workplace culture. Renée Sorrentino describes the "culture of silence" and other destructive factors inherent in the culture of medicine [10]. For decades, many female physician trainees in academic medicine have followed an unwritten rule about pregnancy: "Don't get pregnant, because you don't want to be a problem!" As female students and trainees choose to start families, they often encounter obstacles centered around parental leave and lactation policies. Although it is not often discussed openly, the unspoken message many trainees hear is that they should postpone childbearing and adoption until after training, or at least until their "research years." Addressing the structural elements that result in physicians of both genders sacrificing family life and mental health is crucial, not only for the advancement of female leaders, but also for an equitable and optimal working environment for everyone in gastroenterology and across medicine.

As the Association of Medical Boards adopts a more progressive policy toward parental leaves during training [11], has the graduate medical education community actually embraced a more progressive view on such leaves? If a young physician-in-training progresses from college to medical school, residency, and fellowship, she would typically be 32 when she begins her academic career. This trajectory includes no extra time for gap years, work experience, doctoral or postdoctoral studies, or other "detours." As Magudia and colleagues have shown in their study of trainees at our own multi-hospital system, the vast majority believe that institutions should support trainees as parents [12]. Female trainees are thinking about planning their families, exploring leave policies, and having access to safe and clean lactation rooms, whether or not members of their leadership are talking about these issues or adapting training to meet these needs.

Even those trainees not planning to have children are concerned that they may be impacted by a colleague's parental leave. We must implement creative and innovative initiatives to support progressive leave policies that do not rely upon other trainees for coverage. If a subspecialty field or a particular program is viewed as more supportive of trainees who choose to have children during training, it could be more attractive to female trainees, who take disproportionately more parental leave. In a major shift, trainees are choosing to start and expand their families earlier in their careers. Programs not ready to change with them will likely not match highly competitive candidates. One estimate from the University of Michigan's ongoing study of medical interns states that almost $40 \%$ of women cut back their practice or left the profession early in their careers, with the primary reason listed as: "Family." [13].

Ultimately, increasing female leadership is vitally important to attracting women to subspecialty fields and retaining them in academia. We believe Sethi and colleagues have demonstrated one step of many that, if taken together, will 
yield a more balanced field that will benefit patients and clinicians alike. Although productive programs have been initiated, it is imperative that those most in need gain access to these programs. Furthermore, culture at the local level must include support and advocacy for female gastroenterologists and trainees to connect to these opportunities. Only then we will even begin to approach the equity that will strengthen the practice of not only gastroenterology but also academic medicine at all levels of practice and leadership.

\section{References}

1. Edelman MW. It's hard to be what you can't see. Huffington Post, August 21, 2016. https://www.huffpost.com/entry/its-hard-to-bewhat-you-c_b_8022776. Accessed May 28, 2021.

2. Paturel A. Where are all the women deans? American Association of Medical Colleges, special to AAMCNews, Diversity and Inclusion and Medical Education, June 11, 2019. https://www.aamc. org/news-insights/where-are-all-women-deans. Accessed May 28, 2021.

3. Spaulding Rehabilitation Network News Article. Doctor launches "walls do talk" challenge to combat gender stereotypes in medical schools, November 14, 2017. https://spauldingrehab.org/about/ news/walls-do-talk-challenge. Accessed May 28, 2021.

4. Active Physicians by Sex and Specialty, 2019. 2020 AAMC Physician Specialty Data Report: Executive Summary, Association of American Medical Colleges.

5. Sethi S, Edwards J, Webb A, Mendoza S, Kumar A, Chae S. Addressing gender disparity: increase in female leadership increases gender equality in program director and fellow ranks. Dig Dis Sci 2021. https://doi.org/10.1007/s10620-020-06686-5. (ePub ahead of print).
6. AAMC Statement on Gender Equity, Association of American Medical Colleges, Approved by the 2018-2019 Board of Directors. Accessed May 28, 2021.

7. Travis AC, Katz PO, Kane SV. Mentoring in gastroenterology. Am J Gastroenterol 2010;105:970-972. https://doi.org/10.1038/ ajg.2010.19.

8. Lindenmeyer CC, May E. Hepatology Mentorship: a bold idea: data from the emerging liver scholars program. Hepatol Commun 2018;2:113-119 (first published December 12, 2017).

9. Paturel. Where are all the women deans? 2019.

10. Me Too Movement Long Overdue in Medicine, Psychiatry. Report on presentation by RM Sorrentino: The \#MeToo Movement: Implications for psychiatrists. Presented at American Psychiatric Association Annual Meeting; May 1-3, 2012 (virtual meeting). https://www.healio.com/news/psychiatry/20210511/me-toomovement-long-overdue-in-medicine-psychiatry. Accessed May 28, 2021.

11. American Board of Medical Specialties Policy on Parental, Caregiver and Medical Leave During Training (effective July 1, 2021), American Board of Medical Specialties. https://www. abms.org/policies/parental-leave/. Accessed May 28, 2021.

12. Magudia K, Ng TS, Bick AG, Koster MA, Bay C. Parenting while in training: a comprehensive needs assessment of residents and fellows. J Graduate Med Educ 2020;12:162-167. https://doi.org/ 10.4300/JGME-D-19-00563.1 (Published April 1, 2021).

13. Paturel A. Why women leave medicine. Association of American Medical Colleges, special to AAMCNews, Diversity and Inclusion, Wellness, Workforce. October 1, 2019. https://www.aamc. org/news-insights/why-women-leave-medicine. Accessed May 28, 2021.

Publisher's Note Springer Nature remains neutral with regard to jurisdictional claims in published maps and institutional affiliations. 